\title{
Contaminação do mundo da vida: que filosofia surge de um espirro?
}

\author{
Contamination of lifeworld: which philosophy rises from a sneeze?
}

\section{Eduardo de Borba*}

Resumo: Que tipo de reflexão a filosofia pode fazer sobre uma pandemia? Em virtude do caráter singular da COVID-19, proponho uma leitura em termos de uma análise funcionalista das crises. Para chegar nisso, faço primeiro uma avaliação mais ampla do que há de comum ao nosso tempo, apresentando-o nos termos de um processo de consolidação e expansão do neoliberalismo como uma "gramática normativa central" para a organização e reprodução dos sistemas de reprodução social e agindo de forma colonizadora sobre os processos de reprodução simbólica da sociedade. A apresentação do neoliberalismo pretende enfatizar que, antes da pandemia, já vivíamos em crise e que, por isso, seria preciso uma descrição primeira desse "estado de coisas". Depois, faço uma análise do caráter funcional das sociedades do capitalismo tardio para concluir apontando as perspectivas de aprendizado que a situação de crise permite e como o neoliberalismo impõe uma gramática que contamina esse potencial.

Palavras-chave: Neoliberalismo; Diagnóstico de tempo; Crise; Legitimação

Abstract: What kind of reflection can philosophy make about a pandemic? In view of the unique character of COVID-19, I propose a reading in terms of a functional analysis of the crises. To arrive at this, I first make a broader assessment of what is common to our time, presenting it in terms of a process of consolidation and expansion of neoliberalism as a "central normative grammar" for the organization and reproduction of social reproduction systems and acting in a colonizing manner on the processes of symbolic reproduction of society. The presentation of neoliberalism intends to emphasize that, before the pandemic, we were aliready in crisis and that, therefore, we would need a first description of this "state of affairs". Then, I analyze the functional character of late capitalist societies to conclude by pointing out the learning perspectives that the crisis situation allows and how neoliberalism imposes a grammar that contaminates this potential.

Keywords: Neoliberalism; Time diagnosis; Crisis; Legitimation

Já vão quatro meses desde que a Terra parou. 0 que poderia ser uma afirmação meramente metafórica, tomou conotações tragicamente reais. Conforme a pandemia do COVID-19 alastrava-se pelo mundo, nossa vida tal qual a conhecíamos também mudava junto. Se nos primeiros três meses do ano a crise parecia distante, fora de nossos domínios nacionais, ocorrendo aqui pela "via da importação", ao menos desde início de março, com as primeiras transmissões comunitárias, a pandemia tornou-se um problema real também para nós brasileiros ${ }^{1}$. Desde então, a vida entrou em suspensão. Entramos em quarentena a contragosto do Presidente, saímos dela sem que ela tenha acabado - em termos práticos, quase nunca atingimos a meta de $70 \%$ de população em isolamento. Os motivos para a baixa adesão são vários, mas tudo indica que o mais desolador continua sendo aquele da ordem da necessidade: quem tem fome continua com pressa, com ou sem vírus. A necessidade do trabalho se impõe como condição existencial (ainda que não como queria o jovem Marx) em um sistema baseado no assalariamento (formal, informal, nas formas da viração). Nada mais insensato do que o falso lugar comum que a pandemia atinge a todos igualmente ${ }^{2}$.

\footnotetext{
1 Embora o primeiro caso de transmissão comunitária tenha ocorrido em 06/03/2020, o governo apenas declarou oficialmente a situação em 20/03/2020. Disponível em: https://www.saude.gov.br/noticias/agenciasaude/46568-ministerio-da-saude-declara-transmissao-comunitaria-nacional, acessado em 29/04/2020

2 CARVALHO, L. Como a pandemia pode aprofundar nossa desigualdade
} *Doutorando em Filosofia na Universidade Federal de Santa Catarina, Florianópolis, SC. E-mail: eduardodborba@gmail.com
ORCID: https://orcid.org/0000-0002-3835-9014 
Minhas intenções neste texto são duas: dado esse fenômeno específico de uma experiência objetiva e coletiva de interrupção grave na ordem da vida, pretendo pensar em como a filosofia pode tentar um enquadramento para o problema. Para chegar nisso, faço primeiro uma avaliação mais ampla do que há de comum ao nosso tempo, apresentando-o nos termos de um processo de consolidação e expansão do neoliberalismo como uma "gramática normativa central" específica de um sistema da sociedade que coloniza com seu medium os demais processos de reprodução simbólicos ${ }^{3}$. A apresentação do neoliberalismo pretende enfatizar que, antes da pandemia, já vivíamos em crise e que, por isso, seria preciso uma descrição mais detida sobre esse "estado de coisas".

Feito isso, passo a discutir o neoliberalismo como essa forma específica de capitalismo financeirizado onde as crises, mais do que esporádicas, transformam-se em condição de funcionamento do sistema, perdendo sua abertura para uma possibilidade de resolução terapêutica e nos atrelando a uma espécie de camisa-de-força teórica: "A radicalidade da crise é evitada, mas a crise em si não é resolvida. A própria crise está em crise: estamos presos a uma metacrise" 4 . Encaminho nesse sentido pois compartilho da percepção de que a pandemia do COVID-19 constitui uma crise específica, com particularidades próprias que, no entanto, não constituem um novo tipo de $\mathrm{crise}^{5} \mathrm{em} \mathrm{si}$; ainda "vivemos todos no mesmo país chamado capitalismo"6. Disto, parto para uma exposição rápida das relações funcionais de nossa sociedade seguindo o "modelo" habermasiano esboçado em Problemas de legitimação no capitalismo tardio. Presentificando o diagnóstico frente ao quadro teórico, concluo tentando avaliar aquilo que há de normativamente novo em um processo de crise, a saber, os potenciais de aprendizado que surgem nas frestas e vincos abertos por ela. Nesse momento, poderei apenas lançar luz sobre as consequências de algumas medidas que estão sendo tomadas, especificamente naquelas que dizem respeito à relação entre estado, economia e sociedade.

No entanto, é preciso uma ressalva teórica: se ao menos desde Hegel sabemos que a coruja de Minerva só alça voo ao cair do crepúsculo, o espanto, que aos gregos bastava como impulso inicial, não seria suficiente para uma filosofia consciente de suas limitações? Tomo que que sim e, nesse espírito, pergunto: Que tipo de espanto gera um espirro? Quais são as exigências reflexivas que o momento impõe e qual o tipo de resposta que ela permite oferecer? Quero, nessa tentativa, evitar dois equívocos: o primeiro, de encaminhar um texto na direção de uma mera descrição dos fenômenos que temos enfrentado, quase como um "diário da quarentena". Um segundo percurso a ser evitado é aquele que, no intuito de fornecer uma explicação que faça referência aos fenômenos de autocompreensão da sociedade, acabe por fornecer uma explicação totalizante. Por isso, embora eu apresente o neoliberalismo como uma gramática normativa, quero evitar os problemas de tratá-lo como uma "razão totalizante"7. Tampouco quero comprar o modelo de "crítica da ideologia", explicitamente rechaçado como uma possibilidade metodológica para Habermas. Quero apenas enfatizar a funcionalidade que a ideologia neoliberal do individualismo e da

\footnotetext{
3 Fazendo uma referência clara a tese madura da "colonização do mundo da vida pelos sistemas". Aqui a inspiração são as análises políticas que Habermas realiza a luz de seus escritos de caráter mais teórico. 0 par "A nova obscuridade" e "O discurso filosófico da modernidade" expressam na separação temática entre escrito político e escrito filosófico essa passagem. A inspiração da passagem em si, portanto, encontra nas análises que Habermas faz do neoliberalismo sobretudo em seus textos políticos mais recentes como "Constelação pósnacional" e "Na esteira da tecnocracia".

${ }^{4}$ AZMANOVA, Anti-capital for the XXIst Century (on the metacrisis of capitalismo and the prospects for radical politics, p. 4

5 CESARINO, Coronavírus como força de mercado e o fim da sociedade?

${ }^{6}$ BOON JOON-HO, Entrevista concedida para Kate Hagen e disponível em: https://blog.blcklst.com/the-black-listinterview-bong-joon-ho-on-parasite-5fd0cb0baa12, acessado em: 29/04/2020. A ironia inusitada que atrela o fato de um filme asiático chamado Parasita ser talvez a melhor expressão imagética da funcionalidade que a desigualdade e a insegurança assumem para a manutenção do capitalismo e que se faz visível agora sobre a forma da pandemia só pode ser isso, uma ironia inusitada.
}

${ }^{7}$ DARDOT, LAVAL. A nova razão do mundo. Ensaio sobre a sociedade neoliberal. 
inexistência da sociedade exerce, tendo como efeito prático a anulação da política enquanto atividade cooperativa de resoluções de problemas em comum.

Feita as ressalvas metodológicas, começo tocando no que há de objetivo em uma situação de crise: a necessidade de respostas práticas frente a um contexto problemático que inviabiliza a continuidade da vida de forma normal. E, aqui, um primeiro problema. Embora a Terra tenha parado recentemente, seria otimismo demasiado acreditar que ela vinha girando bem até então. Ao menos desde de 2008 vivemos em um estado de crise permanente, forjando nossa própria capacidade de experienciar uma crise como tal. Mas as raízes da questão, ao menos na tratativa que quero dar aqui, são mais antigas. Embora as experiências de crise econômica sejam constitutivas do capitalismo em suas várias formações, a situação em que nos encontramos hoje e as consequências de uma pandemia como a COVID-19 para a reprodução funcional e simbólica da sociedade devem buscar sua explicação no bojo de um fenômeno social mais complexo, a saber, o avanço de uma ideologia neoliberal sobre a imaginação política.

Mas do falamos quando falamos de neoliberalismo ${ }^{8}$ ? Aqui, apesar da gigante bibliografia sobre o tema, estou mais interessados em entender um certo consenso ideológico que o mantém, na medida em que fortalece uma visão monológica das relações humanas, tanto do ponto de vista da individualidade, quanto sobre a perspectiva da sociabilidade. Nesse sentido, Hartmann e Honneth ${ }^{9}$ observam que a partir da década de 1960, as "demandas de autorrealização individual" sofreram um grave processo de padronização institucional, e, assim sendo, perderam seu próprio motivo de ser enquanto forma de formação do Eu, tornando-se, paradoxalmente, em um caminho aberto para fomentar a própria legitimação do sistema capitalista enquanto tal. 0 ideal de autorrealização, em vez de fornecer a trilha do processo de emancipação do indivíduo convertera-se em imposição, em uma demanda institucionalizada que o força a essa saída, tornando-se um imperativo da nova forma de vida, e não uma possibilidade de autonomia. Para o argumento que tentarei avançar, é importante captar a dimensão em que uma forma de economia que se libertou das amarras sociais, assumindo a figura que já na década de 1940, Karl Polanyi ${ }^{10}$ descrevia como um "moinho satânico", onde "em vez do sistema econômico enraizar-se nas relações sociais, estas passaram a enraizar-se nos sistemas econômicos." Passa a contar com o assentimento (ainda que o caráter consciente desse assentimento seja problemático e não será o foco aqui tratado) até mesmo de suas vítimas.

Para um esclarecimento mais esquemático, recorro a uma tipologia de Wendy Larner ${ }^{11}$, que diferencia o neoliberalismo como uma política (na tradução de policy), como ideologia e como governamentalidade. Como política de Estado, o neoliberalismo pode ser resumido em cinco valores ideais: liberdade de escolha, proteção ao mercado, laissez-faire e governo mínimo. Já entendendo o neoliberalismo de uma perspectiva mais sociológica, seu caráter ideológico define-se pela conclusão de que o poder "é produtivo, e que as articulações entre reinvindicações hegemônicas e contra hegemônicas dão nascimento a novas formas de identidade e subjetividade, que por sua vez, passam a serem discursos de reestruturação"12. E, por fim, o neoliberalismo como uma governamentalidade ${ }^{13}$ deve ser compreendido como um

\footnotetext{
8 Nessa primeira parte, revisito alguns argumentos que apresentei no capítulo IV de minha dissertação de mestrado, Sobre a meritocracia

${ }^{9}$ HARTMANN, HONNETH, Paradoxes of capitalismo, p. 43, tradução do autor

10 POLANYI, A subsistência do homem e ensaios correlatos, p. 221

11 LARNER, Neoliberalism: Policy, Ideology and Governamentality, p. 12, tradução do autor

12 Ibiem, 12, tradução do autor.

13 Aqui a referência evidente é a obra de Michel Foucault, sobretudo seus últimos trabalhos sobre biopolítica e neoliberalismo que se encontram nas aulas de $1^{\text {o }}$ de fevereiro de 1978 e 8 de fevereiro de 1978 e compiladas em Segurança, território e população. Para Foucault, a governamentalidade devia ser entendida como "o processo, ou antes, o resultado do processo pela qual o Estado de justiça da Idade Média, que nos séculos XV e XVI se tornou o estado administrativo, viu-se pouco a pouco "govermentalizado" (FOUCAULT, Segurança, território e população,
} 
sistema de produção de significados que constituem instituições, práticas e identidades de formas contraditórias e disruptivas. Se a primeira característica, aquela que diz respeito às políticas práticas de implementação podem não servir como uma bom parâmetro, já que muitas das vezes vemos relações contraditórias entre seu ideal e aplicação, as duas outras definições me serão mais caras ao tentar avançar a ideia de que o neoliberalismo, ao moldar as formas permissíveis de individualidade (ao menos socialmente úteis), utiliza-se e reforça uma forte ideia de oposição entre individuo e sociedade, cristalizando duas máximas de Margaret Thatcher: a "de que a economia é o método, o objetivo é mudar o coração e a alma" e que, "não existe essa coisa de sociedade, tudo que há são indivíduos e famílias". Volto rapidamente a este ponto na conclusão.

Trata-se, então, de avaliar aquilo que o neoliberalismo realmente é, e não o que ele aparenta - e faz parecer - ser. E, como é o caso agora, evidenciar como o modo neoliberal de gestão da economia e das vidas implica em um tratamento da pandemia do COVID-19 que o enxerga como um problema externo, "como um pensamento exógeno que apresenta as coisas no mundo como naturalizadas, produtos de uma força exterior"14.A pandemia, vista das lentes neoliberais, afronta a economia de fora e, ao fim e ao cabo, realiza a "utopia suicida" de uma vida que, face aos problemas compartilhados da sociedade, só dispõe de saída individualistas e não-cooperativas. Essa tendência a naturalização teve e tem um apelo muito direto ao sensocomum, mostrando-se muito efetiva para sobrepor questões de classe e, finalmente, para colocar os vencedores e perdedores do neoliberalismo atados a um mesmo jogo narrativo: aquele que prosperou vê no discurso neoliberal uma confirmação de seu mérito; o perdedor, vê justificada sua derrota por uma incapacidade própria de responder às demandas do sistema.

Em tempos de pandemia, a clivagem se faz ainda mais aguda: pacientes contaminados e aqueles que se encontram em situação de desamparo são largados à própria sorte, sofrendo nos pulmões e na alma com o descaso de um sistema econômico e político que, girando a esmo em torno da falsa dicotomia entre economia ou saúde, furta-se do imperativo político e moral de agir. Atua assim ao não atuar, confirmando e repondo a situação de fragilidade e desamparo daqueles e daquelas que necessitam do auxílio de um sistema de cooperação social no quais se encontram desde o nascimento e que, sob o ponto dos critérios da justiça social, tem justamente essa tarefa: dividir os benefícios e vantagens que resultam da consequência do fato que vivemos nossas vidas de forma interdependente e imersos em um mesmo pano de fundo, palco para a realização de nossos próprios planos individuais. Decorrem, portanto, do simples fato de que vivemos em sociedade ${ }^{15}$.

Essa tendência à naturalização, já mencionada, assumiu diferentes contornos e especificidades que podem ser condensadas em três processos historicamente situados e politicamente conduzidos: 1) protoneoliberalismo: período do desenvolvimento intelectual da concepção, basicamente restaurando o tipo de pensamento de mercado dentro da teoria econômica; 2) o "neoliberalismo retrativo" (rollback neoliberalism): associado às medidas tomadas por Tatcher e Reagan, onde o poder do Estado mobilizava-se em torno de projetos de "mercadologização" e desregulamentação com alvo principalmente nas políticas de Bem-Estar Social; 3) o "neoliberalismo expansivo" (rollout neoliberalism): consiste no contra-movimento

p 144). A reapropriação da categoria realizada por Wendy Brown encontra-se sistematizada no segundo capítulo de Undoing the demos: Neoliberalism's Stealth Revolution. Para uma avaliação das questões postas pela teoria foucaultiana para a perspectiva da Teoria Crítica da Sociedade, e, portanto, afim com o debate que levanto neste artigo, ver White, Foucault's challenge to Critical Theory

14 Ibidem, p. 382-383

${ }^{15}$ RAWLS, Uma teoria da justiça, p.4-5 
aos efeitos nefastos da forma centrada absolutamente na competição de mercado, ampliando o arsenal de práticas e políticas neoliberais de controle e governança para além dele ${ }^{16}$.

É nessa última fase que podemos também acomodar a definição de Nancy Fraser de um "neoliberalismo progressista", que mais do que apontar um elogio ao momento e configuração específico dessa forma, quer lançar luz ao fenômeno de cooptação dos próprios ideais emancipatórios de autonomia, os torcendo de modo a torná-los uma estratégia de justificação da ofensiva individualista que promete libertar por meio do mercado e da iniciativa individual. Meio este que, contraditoriamente, é o impeditivo de superação próprio modo de pensar próprio ao neoliberalismo e de recondução de uma forma de vida guiada coletiva e cooperativamente ${ }^{17}$. Importa-me mostrar esses três movimentos para reafirmar dois pontos importantes, que muitas vezes vão contra os próprios intuitos do projeto neoliberal: por meio de uma análise histórica, conseguimos demonstrar que este fenômeno tem um caráter contingente, sendo um processo que se desenrola ao longo do tempo, e justo por ser contingente, está aberto para a política, não sendo obra da divina providência, mas responsabilidade dos próprios homens e mulheres. Ou, ainda mais ao encontro do meu interesse aqui, mostrar que embora não hajam culpados pelo aparecimento da COVID-19, as maneiras que nós, enquanto sociedade lidamos com esse fenômeno, toma, invariavelmente, expressões políticas.

Definido esse "pano de fundo neoliberal", que acaba por fornecer uma espécie de contraste para as próprias possibilidades de ação política em nossas sociedades, parto para um esclarecimento mais funcional de como a crise do COVID-19 impõe problemas de reprodução para as ordens sociais estabelecidas à maneira que Habermas as formulou em Problemas de legitimação do capitalismo tardio. Tomando as precauções necessárias à atualização de um modelo que buscava respostas para uma crise oriunda de uma fase justamente anterior ao estabelecimento do neoliberalismo, ou seja, aos problemas de integração sistêmica e social decorrentes de um "capitalismo estatalmente organizado", localizado nos centros da economia capitalista e que, teve como forma política, o Estado de Bem-Estar Social, passo a uma análise um pouco mais detida de como esse modelo se desenvolve em Habermas e como ele pode nos servir ainda hoje como ferramenta de orientação.

É preciso, portanto, analisar a singularidade de uma crise que ocorre em um sistema social específico, o capitalismo tardio, perguntando pelas causas imanentes que expliquem suas ocorrências. Aqui, as preocupações que antes levantava sobre o neoliberalismo, aparecem expressas no sistema das motivações e da legitimação. Nesse sentido, quando falo de capitalismo tardio, estou falando de um sistema social que tem, como princípio funcional básico a reprodução econômica em termos da produção de excedente, sobretudo na forma de lucro. 0 neoliberalismo, nesse quadro habermasiano, funcionaria mais como uma maneira de intromissão do sistema econômico sobre o sistema das motivações e de legitimação.

Faz-se também essencial discernir aquilo que é o funcionamento normal (ainda que, como mostrou a crítica marxiana, contraditório) da sociedade capitalista tardia de uma situação de crise. Em Problemas de legitimação, estas só podem ocorrer quando os "membros da sociedade experienciam alterações sociais como críticas para sua própria existência continuada e sentem suas identidades sociais ameaçadas"18. É essa preocupação, com a estrutura normativa da sociedade, que complementa o que seria a parcialidade de uma abordagem meramente funcionalista do sistema social.

Então, como funciona o argumento de Habermas no texto em questão? De princípio, note-se que o livro apresenta uma insipiente tentativa de apresentação de duas perspectivas

16 COLLIER, The spatial forms and social norms of "actually existing neoliberalism: toward a substantive analytics,

17 FRASER, The End Of Progressive Neoliberalism

18 HABERMAS, Legitimation crisis, p. 3 
de teoria social: uma teoria da ação, focada na perspectiva do agente, e uma teoria dos tipos de ordem social, abordando a perspectiva da estrutura. Se esse trabalho só fora apresentado em sua forma definitiva no segundo volume de Teoria do agir comunicativo, as intuições que aparecem em Problemas de legitimação são valiosas conectar as duas perspectivas sob uma "utilidade empírica da teoria dos sistemas para uma análise das crises econômicas e administrativas"19. 0 projeto pode ser então caracterizado como a "tentativa de fornecer um mecanismo geral para modelar as relações entre os níveis de legitimação e os demais fenômenos macrossociais" $20.0 u$, em uma frase de sintética, em um "esboço de sistematização da teoria ainda sem sistemas". Esse momento insipiente, que define a produção de Habermas nas décadas de 60 e 7021, é exemplar pois emula as mesmas condições sociais que, acredito, enfrentamos agora: por um lado, vemos o visível questionamento das formas atuais de solução de problemas e, de modo mais geral, às próprias capacidades para a continuidade do sistema capitalista financeirizado tal qual o conhecemos. Por outro, ainda não dispomos de um modelo que explique as raízes dessa contestação e que, sobretudo, possibilite perspectivas de alternativas a serem perseguidas.

Dito isso, as ordens sociais são analiticamente estruturadas em três subsistemas: os sistemas econômico, administrativo e sociocultural. Enquanto o sistema econômico e o sistema administrativo possuem a função de regular os mecanismos de controle da sociedade, ou seja, representam os mediums de integração sistêmica, o sistema sociocultural é aquele responsável pela integração social, ao passo que se estrutura e reproduz pelo meio da comunicação intersubjetiva entre os atores com vistas ao entendimento. 0 que aqui aparece como integração sistêmica e integração social, em Teoria do Agir Comunicativo tomará a forma da ação funcionalista e da ação comunicativa, respectivamente ${ }^{22}$.

Não pretendo reconstruir aqui a gênese da diferenciação entre sistema e mundo da vida na obra habermasiana. Quero apenas enfatizar que a apresentação "funcionalista" dos sistemas sociais tem a importância teórica de permitir "topografar" as relações de fluxo entre os diferentes subsistemas, frisando a qualidade singular do sistema sociocultural em criar motivação, o recurso que é utilizado como input tanto do sistema econômico quanto do sistema administrativo. Em situações de capitalismo estatalmente organizado, o Estado necessita de poder legítimo para validar sua interferência no sistema econômico (ainda que essa interferência tenha como propósito a manutenção do "princípio de organização" da sociedade, e, nesse caso, garantir a própria capacidade de existência do sistema econômico capitalista). Para cumprir sua função de impor decisões administrativas de maneira soberana, ele precisa de um input de lealdade das massas de maneira mais ampla possível (organizada pela democracia burguesa formal no sistema de legitimação). Como contraparte, a administração, agora na forma histórica do Estado de Bem-Estar, oferta políticas de compensação social para os riscos e desvios oriundos do sistema econômico. Quando as crises se dão na saída do sistema administrativo (output), tem-se crises de racionalidade: o sistema administrativo não consegue cumprir com as tarefas que assumiu frente o sistema econômico. Essa incapacidade desestrutura objetivamente as formas de vida. Crises de entrada (input) tomam a forma de crises de legitimação, onde o sistema legitimador (que, é apartado funcionalmente do sistema administrativo) não mais mantém o nível exigido de lealdade das massas ${ }^{23}$.

\footnotetext{
${ }^{19}$ HABERMAS, Communicative action - Essays on Jürgen Habermas's The Theory of communicative action, p. 251

${ }^{20}$ HEATH, Legitimation crisis in the later work of Jürgen Habermas, p. 31

21 PEREIRA, Student und Politik e as orignes da segunda geração da Teoria Crítica: Habermas e o diagnóstico do capitalismo tardio nos anos 60, p. 188

22 COOKE, Language and reason, p. 20; HABERMAS, Mudança estrutural da esfera pública, p. 66.

${ }^{23}$ HABERMAS, Para a reconstrução do materialismo histórico, p. 442-443; HABERMAS, Legitimation crisis, p. 45 et seq
} 
Com isso, passo à presentificação que havia proposto. Parto, para isso, de uma pergunta formulada por Nancy Fraser contra esse modelo habermasiano: Por quê, mesmo após a ofensiva neoliberal que inicia justamente nos anos 70 e tem seu ápice na crise financeira de 2008, não enfrentamos uma crise de legitimação? Ou, ainda mais especificamente, por quê a crise motivacional que parece ter assolado nossas sociedades ao menos desde a crise de 2008, não tomou a forma política específica de um questionamento da legitimação que um capitalismo neoliberal financeirizado pode fornecer?

Para Fraser, há algo "eminentemente político" que se perde na perspectiva habermasiana e que, segundo sua proposta, pode ser resolvido por meio de uma apropriação da teoria da hegemonia de Antônio Gramsci. Assim, uma teoria da motivação deveria estar baseada na ideia gramsciana de um "senso comum político", que abarcaria concepções historicamente enraizadas sobre a capacidade de agir, o poder público, a sociedade, a justiça e a história e que, seria a melhor forma de mediar a relação entre crise de integração sistêmica e social. Fraser então passa a mostrar como o "capitalismo neoliberal financeirizado" estabelece narrativas que justificam uma visão a-histórica e, nisso, apolítica, da relação entre Estado, economia e sociedade. Concordo com essa descrição, mas questiono os métodos de chegada.

Embora eu mesmo acredite que o quadro referencial tenha mudado e a explicação de Fraser seja correta, a saber, que nos anos 70 o que contava eram os fins e os meios pelos quais o poder público era implementado enquanto hoje o problema parece ser a própria existência e pertinência da ação do Estado na estrutura social, defendo que um tratamento habermasiano para a questão deva se dar não nos termos de uma teoria da hegemonia em si, mas antes, no espaço de formação e de disputa dessas narrativas e contra narrativas. Acredito que o ponto de entrada para entender a crise que hoje enfrentamos seja a análise da esfera pública e, com isso, da relação entre atores sociais, sistemas e o poder legítimo. Se Habermas parece comprar a tese de que "o modo de produção da vida material condiciona o processo de vida social, política e intelectual" 24 , ele não lê esse condicionamento de forma ortodoxa, ou seja, como uma relação de causalidade. Para Habermas, embora o sistema econômico seja a origem das inquietações que se tornam disfuncionais para a manutenção da própria sociedade capitalista, não é ele que define a crise do sistema, uma vez que "os sistemas não são apresentados como sujeitos, e apenas sujeitos podem estar envolvidos em crises".

Essa intuição, que aparece pautada em Problemas de legitimação, também é articulada em Teoria do agir comunicativo (ainda que o que lá eram crises de controle agora apareçam como patologias no mundo da vida):

Entretanto, os desequilíbrios sistêmicos só têm efeitos de crises quando as realizações da economia e do Estado ficam manifestamente aquém de um certo nível de pretensão estabelecido, prejudicando a reprodução simbólica do mundo da vida, ao provocar nele conflitos e reações de oposição. Isso atinge diretamente o componente social do mundo da vida ${ }^{25}$.

Assim, os distúrbios dos sistemas de base só podem ameaçar a existência do próprio sistema social quando "os fundamentos consensuais das estruturas normativas" são tão prejudicados que a sociedade passa a funcionar de forma anômica ${ }^{26}$. Esses fundamentos consensuais das estruturas normativas, agora sim, como mostram os exemplos de Habermas, tem caráter muito mais substancial no mundo da vida dos cidadãos do que uma mera disposição psicológica. Eles são expressos em narrativas ligadas a "componentes das ideologias burguesas" que formam aquilo que Fraser queria buscar em Gramsci: uma ideologia do desempenho, do individualismo possessivo e da orientação para o valor de

\footnotetext{
24 MARX, Prefácio à "Contribuição para a crítica da economia política, p. 47

${ }^{25}$ HABERMAS, Teoria da ação comunicativa - volume II, p. 693

26 HABERMAS, Legitimation crisis, p. 4.
} 
troca ${ }^{27}$. Esses elementos formam dois padrões de motivação que estabilizam tanto o poder político quanto econômico: o privatismo familiar-profissional, que forma os indivíduos com interesses individuais pelo consumo e tempo livre e pela carreira adequada a competição e ao status e o privatismo da cidadania, "que corresponde às estruturas de uma esfera pública despolitizada." Essa esfera pública é despolitizada porque justamente o privatismo familiar profissional implica numa abstinência das questões políticas públicas e um centramento na esfera privada e da família, além do já mencionado programa de compensação do Estado, que torna os cidadãos em "clientes passivos".

É nesse esquema que podemos explicar funcionalmente o impacto da COVID-19. Desde o início do ano as perspectivas econômicas para o capitalismo vinham sendo revisadas para baixo, apontando para um cenário de crise. Pressões oriundas do embate comercial entre China e EUA, a queda do preço do petróleo, além da redução da inversão da taxa de juros da economia estadunidense apontavam nessa direção. No contexto nacional, embora o mercado estivesse satisfeito com seus ganhos de curto prazo, não haviam sinais de melhor nas condições de crescimento do Brasil, posto que desde o início da crise interna em 2014, ficara cada vez mais evidente que nossos problemas se encontravam no lado da demanda efetiva. Não compartilhando desse diagnóstico, o Ministério da Economia insistia em sua agenda de reformas e de medidas pelo lado da oferta, comprometendo os potenciais efetivos de retomada da economia já que o consumo das famílias e das empresas permanecia desaquecido e sem estímulo do governo, os investimentos privados encontravam mais estagnados que nunca e o próprio governo, por seu credo neoliberal, adotava cegamente a agenda da austeridade econômica.

Com o choque exógeno (sob o ponto de vista da macroeconomia) do COVID-19, aquelas perspectivas que já se mostravam ruins tomaram as proporções de uma crise nunca antes vista. Isso porque, ao contrário das grandes crises de 1929 e 2008, a atual pandemia, com sua necessidade de isolamento social, contaminava já de saída a "economia real". Com a impossibilidade de trabalhar e de auferir renda, trabalhadores (formais e informais) viram-se na eminência de um corte abrupto de suas capacidades de consumir e honrar compromissos. As empresas, por sua vez, não tinham como vender seus produtos e serviços. Ao cenário sem precedentes de paralização do consumo e da produção, soma-se aquilo que é de fato, a questão do momento: a necessidade de, como sociedade global, mitigarmos os efeitos da contaminação do vírus e, como estados nacionais, fomentarmos os sistemas de ciência e tecnologia locais que poderiam dar uma resposta sobre as saídas às questões pragmáticas da pandemia além de, evidentemente, prestar socorro e garantir o funcionamento do sistema de saúde em si. E, do ponto de vista político, só existe um agente capaz de "ativar" esses processos de desenvolvimento técnico-científico, bem como de garantir renda e financiamento para as famílias e a empresa: os Estados nacionais. No entanto, essa necessidade de atuação chocou-se com a ineficiência do sistema administrativo de projetar e fomentar saídas, bem como dá própria inversão, junto à opinião pública formada na esfera pública política, de que a urgência da crise dava liberalidade para os instrumentos de medidas anticíclicas por parte do Estado.

Portanto, parece que existem elementos suficientes para afirmar que a tratativa habermasiana de uma crise de motivação não seria meramente moral. Há uma relação entre problemas de integração sistêmica e incolumidade da integração social que só podem ser tematizados enquanto experiências fáticas de cidadãos democráticos. No entanto, é bem verdade que em Problemas de legitimação, Habermas não faz da esfera pública uma categoria central. Nessa obra, a função da esfera pública seria a de direcionar a atenção para áreas

27 Ibidem, p. 75 et seq. 
tópicas, sem, no entanto, explicitar o fluxo dessa atenção (ao menos não do ponto de vista de uma teoria da circulação do poder democrático) ${ }^{28}$. Era de se esperar, que, dado a evidente ameaça que uma pandemia coloca não só para vidas individuais dos infectados, mas para a sociedade como um todo, a esfera pública política conseguisse estabelecer a prioridade do enfrentamento dessa questão como pauta principal da agenda.

Contudo, o que se viu foi justamente a instalação de um falso dilema entre economia e saúde, que só se impõe em uma sociedade que, como tentei mostrar no início do artigo, introjeta no nível das consciências e molda as próprias instituições segundo a lógica do mercado. Afinal, o dilema entre o valor intrínseco de uma vida e o valor das coisas transacionadas no mercado só se apresenta para aqueles que, já de saída, tomam como orientação normativa que tudo está sujeito a precificação, inclusive a vida. Essa espécie de utilitarismo econômico, que opera sobre a premissa da maximização individualista das expectativas, desconhece que a própria economia não funciona num mundo neutro. Se já sabíamos que "o utilitarismo não leva a sério a diferença entre as pessoas"29, sob o neoliberalismo ele parece até mesmo prescindir delas. A economia capitalista não é uma ordem que nos foi dada por uma entidade transcendental tampouco trata-se de um monolítico que aqui se encontra desde o início dos tempos. Ela é fruto de um processo histórico recente, que desde o seu começou funcionou de par com a atuação do Estado, seja como condição institucional, seja com funções ativas de planejamento e execução econômica (como mostra, sobretudo, a história econômica da segunda metade do século XX). E, o mais importante, a economia capitalista continua sendo um mero meio para a satisfação dos desejos e necessidades materiais que são exclusivamente humanas.

Com isso, do ponto de vista reflexivo, o debate público atual não consegue mobilizar os potenciais de aprendizado que emergem do confronto prático com problemas compartilhados da vida comum e que, por sua vez, comprometem a própria viabilidade de uma cooperação não-coercitiva ${ }^{30}$. Trata-se, enfim, de um problema a ser enquadrado no âmbito da razão prática $^{31}$. Remontando a Aristóteles e, de forma canônica a Kant, defendo a reformulação habermasiana de uma razão prática que não tem como mote de investigação se deter sobre as condições dos julgamentos de casos particulares sob critérios generalizáveis, mas, antes disso, de uma "aptidão para descriminar os problemas de diferentes tipos"32. Os resgates dos usos práticos dessa capacidade reflexiva só podem ocorrer - para uma sociedade democrática e para uma filosofia que entenda seu lugar dentro dessa sociedade - procurando a unidade da razão prática dentro "de uma rede de formas públicas de comunicação e práticas nas quase as condições da formação racional da vontade coletiva tomam formas concretas institucionais ${ }^{33}$.

Quando o conservador primeiro ministro britânico Boris Johnson agradece por sua vida ao sistema de saúde público britânico (NHS) e especialmente a dois estrangeiros que lá trabalham, além do gesto de solidariedade e reconhecimento, ele mobiliza também a capacidade que temos de aprender com as situações práticas que mexem com nossas convicções mais profundas. Ao agradecer uma instituição fundamental para o povo inglês e aos indivíduos que, mesmo desterrados, cumprem seus papéis sociais e salvam vidas, até mesmo Johnson eleva o sentido de cura: existe sim, sociedade. E ela se faz de pessoas, não de indivíduos.

\footnotetext{
28 Ibidem, p. 37

${ }^{29}$ RAWLS, Uma teoria da justiça, p. 30

30 BOHMAN, Public deliberation: pluralismo, complexity, and democracy, p. 5

${ }^{31}$ HABERMAS, On the Pragmatic, the Ethical, and the Moral Employments of Practical Reason.

32 Idem, ibidem, p. 17

33 Ibidem, 17.
} 


\section{Referências}

AZMANOVA, A. Anti-capital for the XXIst Century (on the metacrisis of capitalismo and the prospects for radical politics, Philosophy and social criticism, XX, 2020

BOHMAN, J. Public deliberation: Pluralism, complexity and democracy. Cambridge: MIT Press, 1996

BORBA, E. d. Sobre a meritocracia. Dissertação (Mestrado em Filosofia). Centro de Filosofia e Ciências Humanas, Universidade Federal de Santa Catarina, 2017

BROWN, W. American Nightmare: Neoliberalism, Neoconservatism, and De-Democratization. Political Theory, 2006

BROWN, W. Undoing the demos. New York: Zone Books, 2015

CARVALHO, L. Como a pandemia pode aprofundar nossa desigualdade, 2020. Disponível em: https://www.nexojornal.com.br/colunistas/2020/Como-a-pandemia-pode-aprofundarnossas-desigualdades. Acesso em: 29/04/2020

CESARINO, L. Coronavírus como força de mercado e o fim da sociedade? Disponível em: https://www.antropologicas-epidemicas.com.br/post/coronav\%C3\%ADrus-comofor\%C3\%A7a-de-mercado-e-o-fim-da-sociedade. Acesso em: 29/04/2020

COLLIER, S. The spatial forms and social norms of "actually existing neoliberalism. International Affairs Working Paper, Nova Iorque, Junho, 2005.

COOKE, M. Language and reason. A study of Habermas's Pragmatics. Cambridge: The MIT Press, 1997.

HABERMAS, J. Reply. In: Honneth, A; Joas, H. (Orgs) Communicative Action - Essays on Jürgen Habermas's The theory of communicative action. Cambridge: MIT Press, 1991.

DARDOT, P; LAVAL, C. A nova razão do mundo. São Paulo: Editora Boitempo, 2016

FRASER, N. The end of progressive neoliberalism. Dissent, primavera, 2017

FRASER, N. Crise de legitimação? Sobre as contradições políticas do capitalismo financeirizado. Cadernos de filosofia alemã, vol. 23, n. 2, 2018

FOUCAULT, M. Segurança, território, população. São Paulo: Martins Fontes, 2008

HABERMAS, J. A nova obscuridade. São Paulo: Editora da UNESP, 2011

HABERMAS, J. Legitimation crisis. Cambridge: Polity Press, 1988

HABERMAS, J. Justification and application. Cambdrige: MIT Press, 1994

HABERMAS, J. Mudança estrutural da esfera pública. São Paulo: Editora da UNESP, 2014a

HABERMAS, J. Na esteira da tecnocracia. São Paulo: Editora da UNESP, 2014

HABERMAS, J. O discurso filosófico da modernidade. São Paulo: Martins Fontes, 2002

HABERMAS, J. Para a reconstrução do materialismo histórico. São Paulo: Editora da UNESP, 2015

HABERMAS, J. The Postnational constelattion. Cambridge: MIT Press, 2001

HABERMAS, Jürgen. Teoria do Agir Comunicativo - Sobre a crítica da razão funcionalista (volume II). São Paulo: Editora da WMF Martins Fontes, 2012

HARTMANN, M.; HONNETH,. Paradoxes of capitalism. Constellations, v. 13, n. 1, p. 41-58, 2006 
HEATH, J. Legitimation crisis' in the later work of Jürgen Habermas, 2004. Disponível em: http://mapageweb.umontreal.ca/heathj/texts/legitimation.pdf , Acessado em 29/04/2020

LARNER, W. Neo-liberalism: Policy, Ideology, Governamentality. Studies in Political Economy, 63,2000

MARX, K. Contribuição à crítica da economia política. São Paulo: Expressão Popular, 2008

PECK, J.; TICKELL, A. Neoliberalizing Spaces. Antipode, 34/3, 2002

PEREIRA, L.d.H. Student und Politik e as orignes da segunda geração da Teoria Crítica: Habermas e o diagnóstico do capitalismo tardio nos anos 60, Philósophos - Revista de Filosofia, $20(1), 2014$

POLANYI, K. A subsistência do homem e ensaios correlatos. Rio de Janeiro: Contraponto, 2012

RAWLS, J. Uma teoria da justiça. São Paulo: Martins Fontes, 2008

STREECK, W. Tempo comprado: a crise adiada do capitalismo democrático. São Paulo: Editora Boitempo, 2018

WHITE, S. K. Foucault's challenge to Critical Theory. The American Political Science Review, Vol. 80, n. 2, 1986 